\title{
Effect of radial hydrides on the axial and hoop mechanical properties of Zircaloy-4 cladding
}

\author{
H.C. Chu ${ }^{\mathrm{a}, \mathrm{b}, *}$, S.K. Wu ${ }^{\text {a }}$, K.F. Chien ${ }^{\mathrm{b}}$, R.C. Kuo ${ }^{\mathrm{b}}$ \\ a Department of Materials Science and Engineering, National Taiwan University, Taipei 10617, Taiwan, ROC \\ ${ }^{\mathrm{b}}$ Institute of Nuclear Energy Research, P.O. Box 3-14, Longtan, Taoyuan 32546, Taiwan, ROC
}

Received 27 June 2006; accepted 13 November 2006

\begin{abstract}
The effect of radial hydrides on the mechanical properties of stress-relief annealed Zircaloy-4 cladding was studied. Specimens were firstly hydrided to different target hydrogen levels between 100 and $600 \mathrm{wt}$ ppm and then thermally cycled in an autoclave under a constant hoop stress to form radial hydrides by a hydride reorientation process. The effect of radial hydrides on the axial properties of the cladding was insignificant. On the other hand, the cladding ductility measurements decreased as its radial hydride content increased when the specimen was tested in plane strain tension. A reference hydrogen concentration for radial hydrides in the cladding was defined for assessing the fuel cladding integrity based on a criterion of the tensile strength $600 \mathrm{MPa}$. The reference hydrogen concentration increased with the specimen (bulk) hydrogen concentration to a maximum of $\sim 90 \mathrm{wt} \mathrm{ppm}$ at the bulk concentration $\sim 300 \mathrm{wt} \mathrm{ppm} \mathrm{H}$ and then decreased towards higher concentrations.
\end{abstract}

(C) 2006 Elsevier B.V. All rights reserved.

PACS: $62.20 . \mathrm{Fe}$

\section{Introduction}

The mechanical properties of Zircaloy fuel cladding can be adversely affected by the presence of hydrides, especially when they are oriented towards the radial direction of the tubing (i.e. radial hydride). Marshall and Louthan, Jr., demonstrated that Zircaloy-2 tube containing radial hydrides of

\footnotetext{
* Corresponding author. Address: Department of Materials Science and Engineering, National Taiwan University, Taipei 10617, Taiwan, ROC. Tel.: +886 3 4711400x6694; fax: +886 3 4711409.

E-mail address: hcchu@iner.gov.tw (H.C. Chu).
}

more than 50 ppm hydrogen exhibited no macroscopic ductility [1], whereas specimens with circumferentially oriented hydrides at the same hydrogen levels showed better ductility $[2,3]$. In order to retain sufficient ductility to keep its integrity during reactor service, Zircaloy fuel cladding tube is manufactured to ensure that only circumferential hydride platelets are developed due to the hydrogen pickup from the waterside corrosion reaction. However, radial hydrides can be formed when a specimen is cooled down under stress from temperatures at which a fraction of hydrides is dissolved [4-6]. As a result of the larger hoop stress and higher hydrogen concentration attendant with fuel cladding at 
higher burnups, the stress reorientation of hydrides is very likely to happen under some conditions during spent fuel dry storage or reactor operation [7-9].

To assure the cladding integrity, Interim Staff Guidance-11, Revision 3 (ISG-11) is used by the US NRC staff when reviewing analyses of the potential for spent fuel reconfiguration during storage conditions. It contains some limitations on the peak cladding temperature, cladding hoop stress and repeated thermal cycling [10]. These acceptance criteria are applicable for all commercial spent fuel burnup levels less than $45 \mathrm{GW} \mathrm{d} / \mathrm{MTU}$, and are proposed on the basis of the reduction in cladding ductility associated with the formation of radial hydrides. For spent fuel with higher burnups (exceeding $45 \mathrm{GW} \mathrm{d/MTU),} \mathrm{the} \mathrm{analyses} \mathrm{will} \mathrm{be}$ reviewed on a case-by-case basis because the current technical information is still insufficient. Therefore, a proper understanding of the mechanism responsible for the stress reorientation of hydrides in the high-burnup fuel cladding is helpful to license application for spent fuel dry storage and transportation. However, the studies of radial hydrides and relevant influences on cladding tube with higher hydrogen levels are limited. In this work, the hydride reorientation behavior and its effects on mechanical properties of the Zircaloy-4 cladding with hydrogen contents up to $600 \mathrm{wt}$ ppm were investigated. Specimens were firstly hydrided to different target hydrogen levels and followed by thermal cycling under a constant hoop stress to form radial hydrides. Then these specimens with a mixture of circumferential and radial hydrides were tested at room temperature. The effect of radial hydride on the mechanical properties is discussed in this paper.

\section{Experimental}

\subsection{Material and hydriding process}

Stress-relief annealed (SRA) Zircaloy-4 cladding with an outside diameter of $9.5 \mathrm{~mm}$ and wall thickness of $0.58 \mathrm{~mm}$ was used in this study. Its chemical composition is given in Table 1. Cladding tube, cut into $13-\mathrm{cm}$ lengths, was first uniformly hydrogen-

Table 1

Chemical compositions of Zircaloy-4 cladding tube (weight \%)

\begin{tabular}{llllllll}
\hline $\mathrm{Sn}$ & $\mathrm{Fe}$ & $\mathrm{Cr}$ & $\mathrm{O}$ & $\mathrm{N}$ & $\mathrm{C}$ & $\mathrm{H}$ & $\mathrm{Zr}$ \\
\hline 1.26 & 0.22 & 0.12 & 0.13 & 0.0029 & 0.01 & 0.0007 & Balance \\
\hline
\end{tabular}

charged by a thermal cycling process. The specimen was encapsulated with a pre-determined amount of pure hydrogen in a Pyrex capsule of sufficient volume such that a low hydrogen partial pressure could be obtained to avert the formation of hydride layers. The encapsulated cladding specimen was then thermally cycled between $\sim 200^{\circ} \mathrm{C}$ and $300{ }^{\circ} \mathrm{C}$ for a certain number of cycles, depending on the target hydrogen concentration level. The heating and cooling rates were at $3{ }^{\circ} \mathrm{C} / \mathrm{min}$ and $2{ }^{\circ} \mathrm{C} / \mathrm{min}$, respectively. The target hydrogen levels ranged from 100 to $600 \mathrm{wt} \mathrm{ppm}$. Typically, hydrides were oriented in the circumferential direction and homogeneously distributed across the cross-section of the cladding specimen.

\subsection{Hydride reorientation experiment}

In order to obtain radial hydrides, the as-hydrided specimen was further subjected to thermal cycling in an autoclave under a constant hoop stress by regulating the differential pressure between its internal and external pressures with a constant differential pressure control system, as schematically shown in Fig. 1. Prior to the hydride reorientation run, the autoclave was evacuated and then filled with helium gas of $\sim 2 \mathrm{MPa}$ and the cladding specimen was internally pressurized with water at room temperature. Then the tube was heated at a rate of $3{ }^{\circ} \mathrm{C} / \mathrm{min}$ to $400{ }^{\circ} \mathrm{C}$ under a constant differential pressure of 20.7 MPa that was equivalent to a hoop stress of

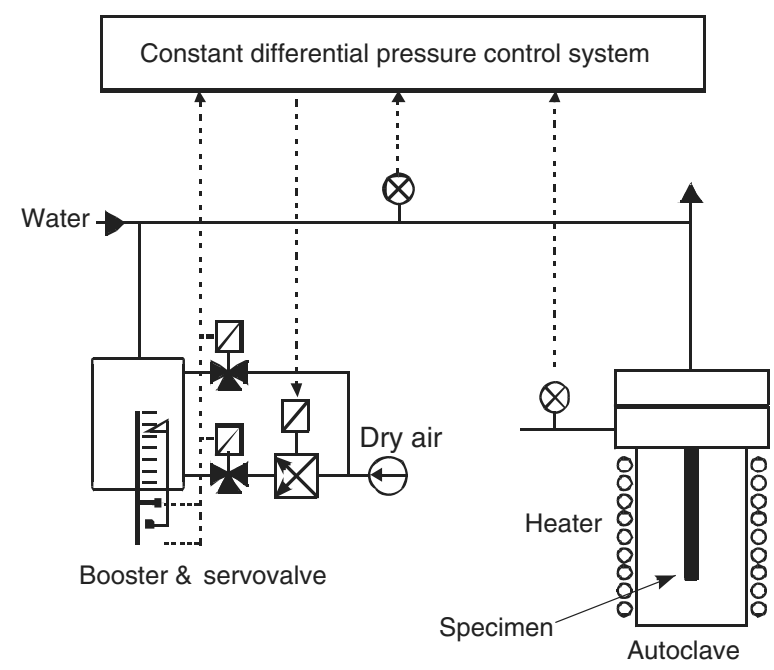

Fig. 1. Schematic diagram of the constant differential pressure control system. 
$160 \mathrm{MPa}$ being applied on the tubing wall. After solution annealed at $400{ }^{\circ} \mathrm{C}$ for $2 \mathrm{~h}$, the specimen was slowly cooled down at a cooling rate of $1{ }^{\circ} \mathrm{C} /$ min to $170^{\circ} \mathrm{C}$ to make up one thermal cycle. Another thermal cycle started once the tube was cooled down to $170^{\circ} \mathrm{C}$. Upon completion of the thermal cycle treatment, the cladding tube was furnace cooled from $170{ }^{\circ} \mathrm{C}$ to room temperature. The pressure fluctuations due to thermal expansion of water and helium gas were regulated and minimized by the constant differential pressure controller, the maximum variation in differential pressure was less than $0.1 \mathrm{MPa}$. During thermal cycling, a fraction of hydride precipitates dissolved at higher temperatures. With the aid of the hoop stress, zirconium hydrides would re-precipitate out with their precipitate planes oriented in the radial direction of Zirclaoy cladding, when the specimen was cooled down. In this work, cladding tubes were treated under the same thermal parameter and differential pressure but different cycling numbers, i.e. 1, 2, 4, 8 and 12 cycles, to obtain specimens with various fractions of radial hydride precipitates.

Transverse sections of tubing specimens before and after thermal cycling were examined by optical microscopy to reveal the hydride morphology and orientation. The etchant used for metallographic examination was composed of $\mathrm{HF}, \mathrm{HNO}_{3}, \mathrm{H}_{2} \mathrm{SO}_{4}$, and $\mathrm{H}_{2} \mathrm{O}$ in a volume ratio of $1: 10: 10: 10$. Hydrogen concentrations of Zircaloy-4 cladding specimens were determined by an inert-gas fusion method using a LECO RH-404 hydrogen determinator. The sample for optical metallographic examination was cut from the same piece for hydrogen analysis.

\subsection{Mechanical test}

Following the reorientation process, the cladding tubes were subsequently cut in two pieces and machined into mechanical test specimens. Two types of test configuration were used: uniaxial tension test (UTT) for axial loading and slotted arc tension (SAT) test for circumferential loading. Detailed dimensions of these two specimens are given in Fig. 2.

\subsubsection{Uniaxial tension test}

UTT tests were conducted on an Instron model 5582 mechanical testing machine at a nominal strain rate of $\sim 1 \times 10^{-4} \mathrm{~s}^{-1}$. A gripping device was designed to provide suitable mate surfaces for the specimen curvature and lateral support to minimize
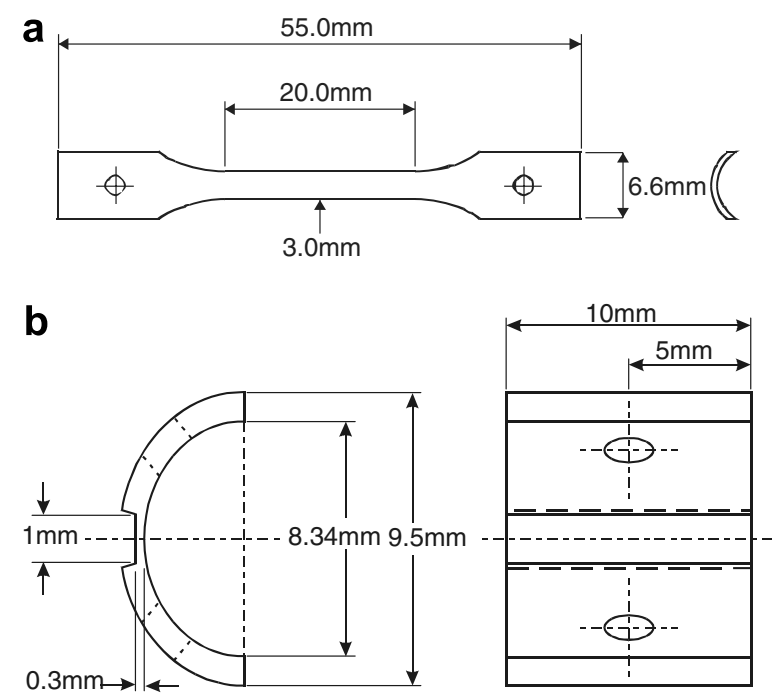

Fig. 2. Dimensions of (a) uniaxial tension specimen and (b) slotted arc tension specimen.

specimen bending that would result from the specimen curvature and fillet arc. The specimen elongation was measured by an LVDT extensometer over the mid-gauge section of $16 \mathrm{~mm}$. The accuracy of the LVDT extensometer is $\pm 0.2 \%$ of reading.

\subsubsection{Slotted arc tension test}

To simulate the loading conditions prevailing on fuel cladding in service, the SAT test was developed to determine the mechanical properties of Zircaloy4 tubing material. Specimens were also tested on Instron mechanical testing machine at a nominal strain rate of $\sim 1 \times 10^{-4} \mathrm{~s}^{-1}$. An anti-bending mechanism was added to the specimen grip with troughshaped guides positioned on opposite ends of the slot, as depicted in Fig. 3. A dual-head optical extensometer was employed to take the strain measurements of an SAT specimen from both sides of its gauge section concurrently during testing. Then the strains were averaged to nullify the counteracting bending effects on both sides of the specimen section. The strain measurements taken by the optical extensometer were verified and calibrated by the strain gauge. The resolution of the extensometer is about $4 \mu \mathrm{m}$.

\subsection{Analysis of hydride orientation}

Since hydride platelets were inclined to precipitate in the form of long stringers and always linked together, the general orientation of hydride stringers 


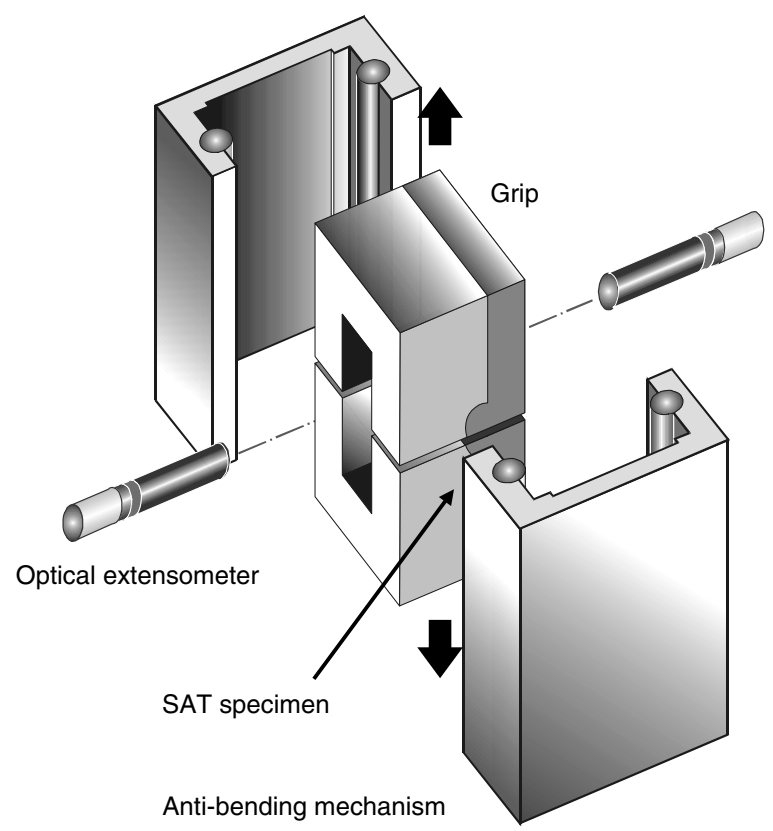

Fig. 3. A sketch of the arrangement of a tension test on a slotted arc tension specimen.

was thus selected to assess the hydride orientation rather than the specific orientation of individual platelets. The majority of hydride traces observed was either along the specimen hoop direction or perpendicular to it, so it was convenient to classify the hydride stringers into two groups: circumferential and radial hydrides. The former was defined as the clusters with their precipitate planes oriented within $0-40^{\circ}$ to the reference (circumferential) axis; the clusters within $50-90^{\circ}$ to the reference axis were recognized as radial hydrides. The small clusters within $40-50^{\circ}$ to the reference axis were classified into neither of the two groups, and not counted into the total amount of hydrides.

The percentage of radial hydrides was determined by calculating the areal fraction of radial strings on a photomicrograph. To provide a highresolution digital image for this analysis, a digital camera with a CCD array of $2048 \times 2048$ pixels was mounted on a microscope to project the hydride traces onto a screen. A magnification of 200 was selected. The orientation of hydride trace was recorded as each pixel in the image was scanned, the fraction of total pixel of hydrides in each category was then determined. On a photomicrograph, the hydride orientation analysis was conducted at two locations in the middle of the cladding wall. From the measurements, the average fraction of radial hydrides was then calculated. Because both radial and circumferential hydride precipitate planes were predominantly parallel to the axial direction of cladding tube, all hydride reorientation data were measured on the transverse cross-section.

\section{Results and discussion}

\subsection{Effect of thermal cycling on hydride reorientation}

An example of the reorientation of hydride precipitates in Zircaloy fuel cladding is given in
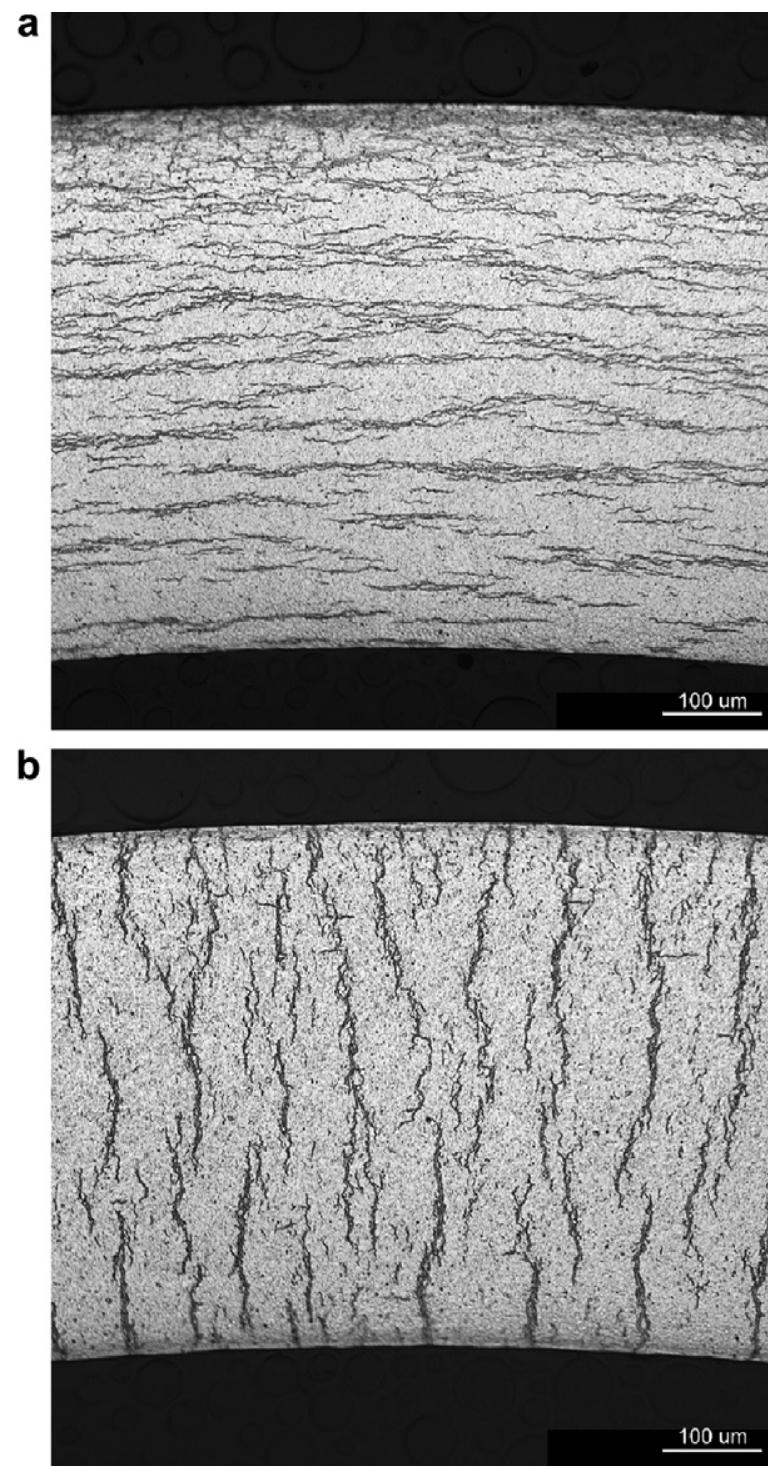

Fig. 4. Micrographs showing reorientation of hydrides in Zircaloy-4 cladding: (a) as-hydrided, (b) after 8 cycles of thermal treatment ( 230 wt ppm). 
Fig. 4. Most hydrides were circumferentially aligned and uniformly distributed across the as-hydrided cladding wall. The majority of the hydride traces was thick and long; there existed a minor amount of fine hydrides. In general, both the coarse and fine hydrides had the same orientation. With increasing the number of thermal cycles, the proportion of these fine hydrides decreased and the reorientation of hydrides from circumferential to radial direction became more noticeable. The slow cooling rate of $1{ }^{\circ} \mathrm{C} / \mathrm{min}$ provided sufficient time for hydrogen atoms to diffuse and precipitate at their preferable sites.

The effect of the thermal cycle number on the reorientation of hydrides in cladding tube is shown to vary with hydrogen concentration in Fig. 5. A hoop stress of $160 \mathrm{MPa}$ was applied on the cladding tube while thermal cycling was proceeding. The percentage of radial hydrides increased as the number of thermal cycles increased, until it reached a plateau value on the reorientation curves plotted in Fig. 5. More than $90 \%$ of hydride precipitates in the 200 $300 \mathrm{wt}$ ppm $\mathrm{H}$ specimens were reoriented into radial hydrides. For the specimen with a higher hydrogen content of $600 \mathrm{wt} \mathrm{ppm}$, the applied stress of $160 \mathrm{MPa}$ induced a maximum of about $20 \%$ radial hydrides after twelve cycles. Besides, a lower plateau value of approximately $78 \%$ radial hydrides was obtained for the $130 \mathrm{wt}$ ppm $\mathrm{H}$ specimen. The fact that the extent of reorientation of hydrides in the cladding with $130 \mathrm{wt}$ ppm hydrogen is lower than those of higher hydrogen content levels is believed to be related to the temperatures at which the

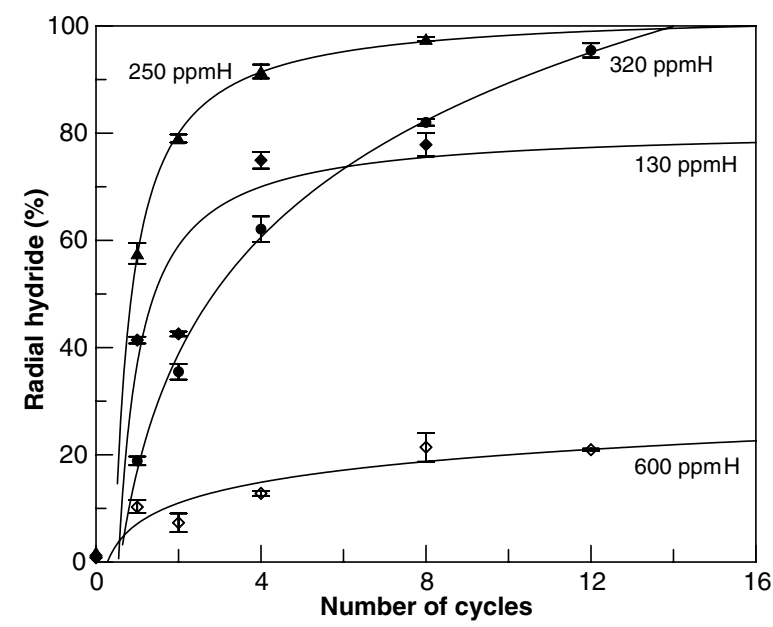

Fig. 5. Effect of the thermal cycle number on the hydride reorientation of cladding tubes with various hydrogen concentrations. hydrides begin to nucleate from the saturated matrix. According to the solubility data [11], a cladding material with hydrogen contents higher than $200 \mathrm{wt}$ ppm would start to have hydrides precipitated when it was slowly cooled from the holding temperature of $400{ }^{\circ} \mathrm{C}$, whereas precipitation in a 130 wt ppm $\mathrm{H}$ specimen did not occur until it was cooled to $357^{\circ} \mathrm{C}$. The diffusion rate of hydrogen atoms was smaller and the effect of the stress on the hydride reorientation was less significant in extent at lower temperatures, relative to those at $400{ }^{\circ} \mathrm{C}$. Consequently, a lower plateau fraction value for radial hydrides was obtained on the cladding specimens with lower bulk hydrogen concentrations.

It is generally believed that stress reorientation takes place only on the hydrides which have dissolved and then re-precipitated under stress. Hence small proportions of hydrides in the 320 and $600 \mathrm{wt}$ ppm $\mathrm{H}$ specimens aligned radially after the first cycle of heat treatment. A complete reorientation of hydrides was attainable on the $320 \mathrm{wt}$ ppm $\mathrm{H}$ specimen after 12 cycles of thermal treatment, whereas there were still about $120 \mathrm{wt}$ ppm of hydrides not dissolved at $400{ }^{\circ} \mathrm{C}$ during each cycle. Results obtained in this work imply that, under a proper combination of cladding temperature and hoop stress, a complete reorientation of all hydrides is possible with the aid of repeated heating and cooling even though hydrides are not fully dissolved in each thermal cycle.

\subsection{Hydrided Zircaloy cladding under tension tests}

\subsubsection{General description}

The uniaxial tension specimens were loaded in a plane stress state and the slotted arc tension specimens in a stress state approaching the plane strain loading condition. A comparison of the typical stress-strain curves for UTT and SAT tests on Zircaloy-4 cladding specimens was exemplified in Fig. 6. Except for the specimens containing radial hydrides, the SAT specimens sustain higher flow stress than the UTT specimens but much smaller ductility, which is similar to the observations of other researches on Zircaloy-2 [12,13]. The higher flow stress of SAT specimens is mostly attributed to the geometry of the plane strain tension specimen [14].

Fig. 7 shows the effect of hydrogen concentration on the mechanical properties of Zircaloy-4 fuel cladding tube tested under uniaxial and slotted 


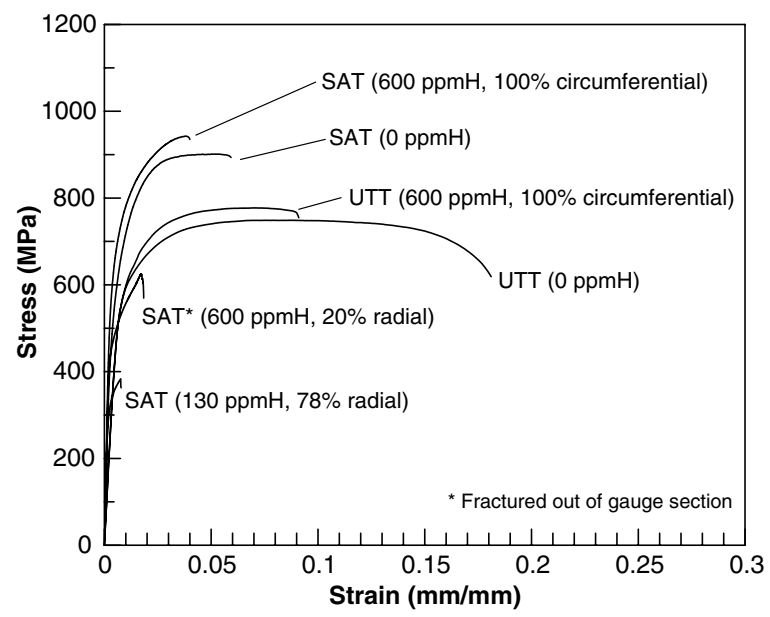

Fig. 6. Typical engineering stress-strain curves for uniaxial and slotted arc tension tests on Zircaloy-4 cladding specimens at room temperature.

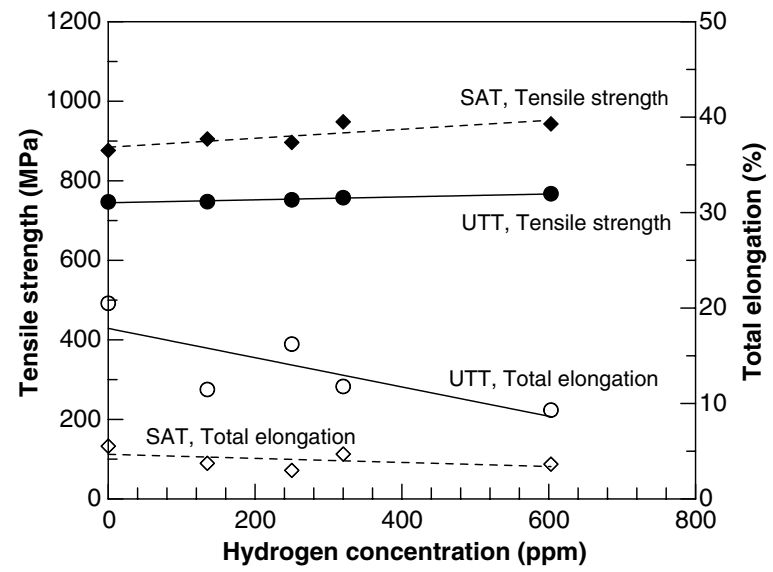

Fig. 7. Effect of hydrogen concentration on the mechanical properties of SRA fuel cladding specimens tested under uniaxial tension and slotted arc tension; all hydrides in specimens were circumferentially aligned.

arc tension at room temperature. All hydrides in this case were homogeneously distributed and completely oriented along the circumferential direction. The tensile strengths of both UTT and SAT fuel cladding specimens increased slightly with hydrogen content, their ductility values decreased as hydrogen concentration increased. These trends are in agreement with the observations by other investigators $[2,3,15,16]$.

Some of the as-received tubes were treated under the same conditions as those for stress-reorientation experiments and tested at room temperature to verify the effect of thermal cycle itself on the deformation behavior of the material. Results of both UTT and SAT specimens showed little or no dependence on the number of thermal cycles.

\subsubsection{Effect of radial hydride on uniaxial tension properties}

The effects of radial hydrides on the uniaxial tensile properties of Zircaloy-4 cladding specimens, with hydrogen concentration levels ranging between 130 and $600 \mathrm{wt} \mathrm{ppm}$, tested at room temperature are plotted in Fig. 8. The effect of radial hydrides on the axial ductility of the cladding tube was insignificant even with the case of $320 \mathrm{wt}$ ppm specimens in which most of hydride platelets were reoriented into radial direction. This phenomenon could be ascribed to the fact that both the face normals of radial and circumferential hydride platelets were perpendicular to the applied stress. The effects of both circumferential and radial hydrides on the mechanical properties of cladding tube along the loading direction were similar.

On the other hand, when cladding tubes were subjected to tensile hoop stress, the radial hydrides with their platelet normals parallel to the stress direction and were susceptible to cracking along the hydride planes, a great loss in the circumferential ductility was expected. The effects of radial hydrides on the cladding hoop properties are discussed in the following section.

\subsubsection{Effect of radial hydride on hoop tension properties}

Fig. 9 shows the effects of radial hydrides on the hoop tensile properties of Zircaloy-4 cladding

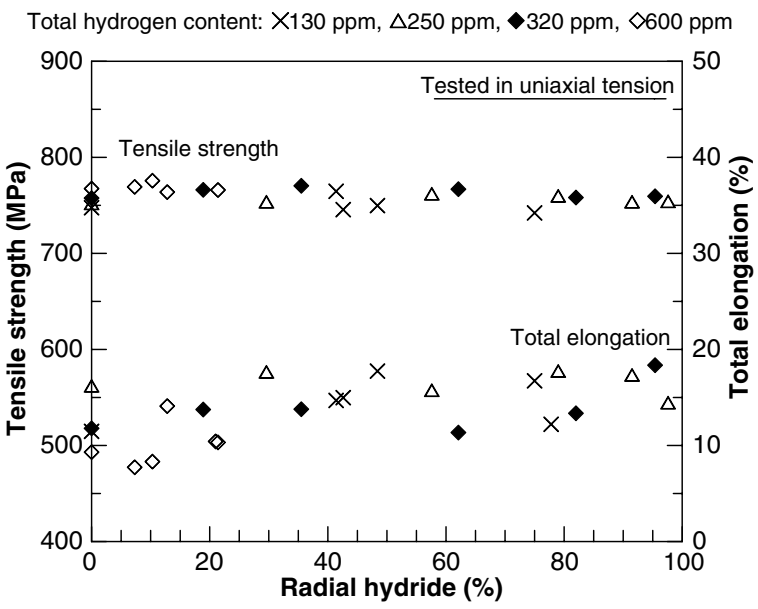

Fig. 8. Effect of radial hydrides on the mechanical properties of SRA fuel cladding specimens tested under uniaxial tension at room temperature. 

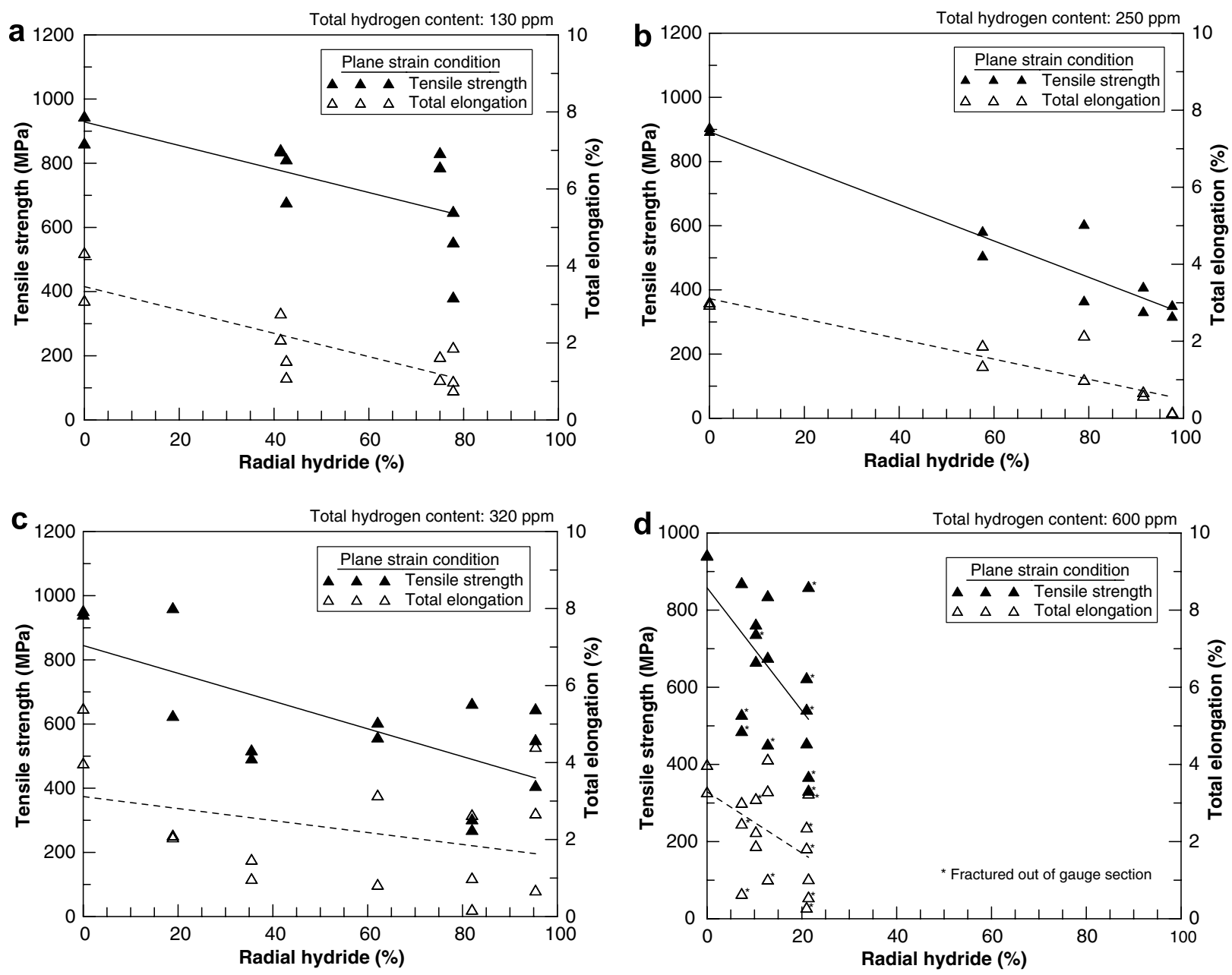

Fig. 9. Effect of radial hydrides on the mechanical properties of cladding specimens with various hydrogen content levels tested under slotted arc tension at room temperature: (a) $130 \mathrm{wt}$ ppm, (b) $250 \mathrm{wt} \mathrm{ppm}$, (c) $320 \mathrm{wt} \mathrm{ppm}$, and (d) $600 \mathrm{wt}$ ppm.

specimens, with hydrogen concentration levels ranging between 130 and $600 \mathrm{wt} \mathrm{ppm}$, tested at room temperature. It was observed that if all hydrides in the cladding were $100 \%$ circumferentially oriented, the test results showed a good reproducibility. Once some of the circumferential hydrides transformed into radial, the hoop mechanical properties of cladding deteriorated and the data became scattered.

Fig. 9 also suggests that some specimens with significant amounts of radial hydrides apparently have sufficient ductility, but that they were very brittle and fractured at stresses lower than the yield strength. For example, the specimens with $600 \mathrm{wt}$ ppm hydrogen failed when deformed in the elastic elongation range, but their stress-strain curves still showed nonlinear responses as if they underwent plastic deformation (Fig. 6). The contra- dictory observation could be ascribed to the formation of some small surface cracks from breaking of radial hydrides during testing. Because the strains were taken by measuring the distance between the two indentations on the gauge section $(\sim 0.7 \mathrm{~mm})$, the formation of surface cracks caused an increment in this distance and thus higher strains were obtained. Choubey and Puls [17] have used acoustic emission (AE) to detect cracking of long radial hydrides in $\mathrm{Zr}-2.5 \mathrm{Nb}$. They reported that cracking of hydrides was initiated in the low plastic region or slightly below the yield stress. And the small numbers of $\mathrm{AE}$ events generated in the early stage of deformation were not considered representative of hydride cracking because of unknown and uncontrolled stresses that might exist in the specimen. In this study, surface cracks appeared succes- 
sively when specimens were gradually loaded up to $\sim 300 \mathrm{MPa}$. Because of the slight bending effect during the initial stage of the test, most of the cracks tended to occur on the specimen inner surface to compensate the slightly different stress levels on both sides of the slotted area.

Fig. 10 illustrates the fractographic features of the specimens tested at room temperature. Normal dimples, ridges and round voids were the dominant features of the as-received specimens
(Fig. 10(a)), the brittle features of microcracks, cleavages increased as hydrogen concentration increased (Fig. 10(b)). For the specimens having $100 \%$ circumferential hydrides, the number of microcracks on the fracture surface increased with increasing hydrogen concentration. As can be seen in Fig. 10(b) and (c) for specimens with the same hydrogen content levels, the number of secondary cracks decreased if some hydrides reoriented into radial direction.

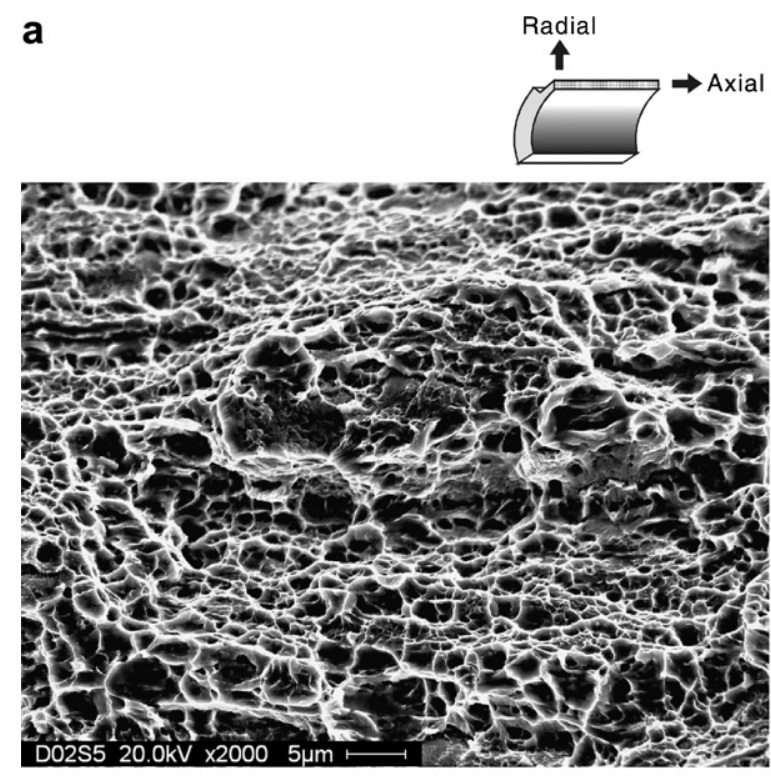

c b

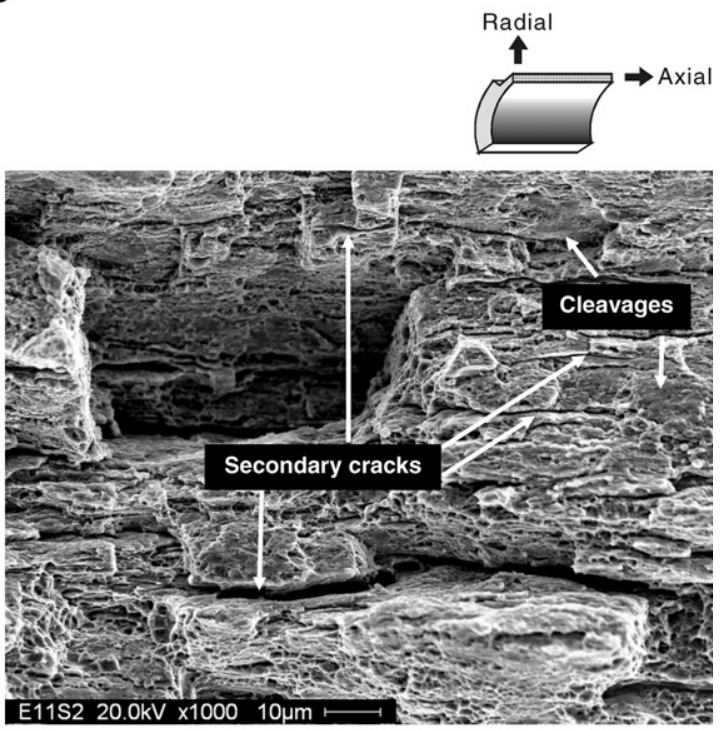

Radial

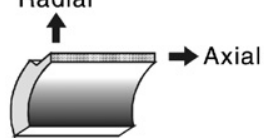

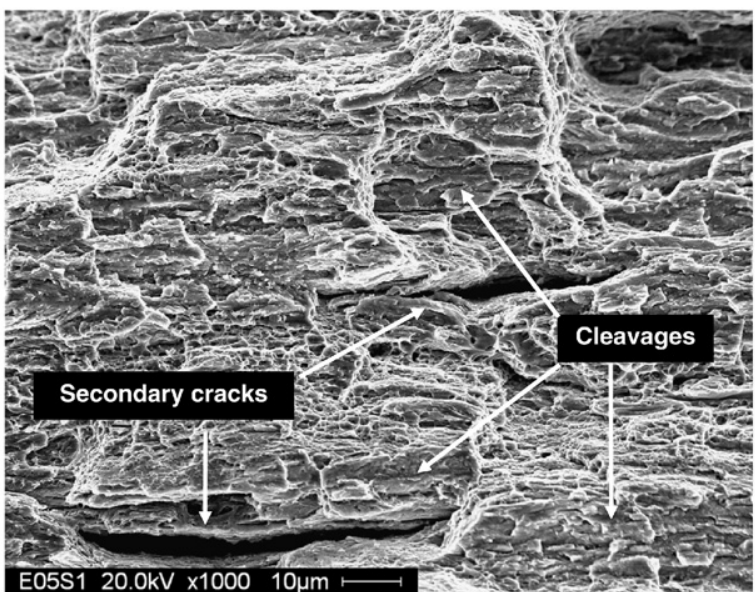

Fig. 10. SEM fractographs of SRA cladding specimens tested under slotted arc tension at room temperature: (a) SRA Zircaloy-4 with $7 \mathrm{wt}$ ppm H (as-received), (b) $600 \mathrm{wt}$ ppm H specimen with $\sim 100 \%$ circumferential hydrides, and (c) $600 \mathrm{wt}$ ppm H specimen with $\sim 21 \%$ radial hydrides. 
To better understand the cladding deformation behavior along the hoop direction, toughness was used to evaluate the effect of radial hydrides on the mechanical properties of cladding tube. The toughness was obtained by calculating the total area under the stress-strain curve [18]. It was an indicator which showed that the amount of work per unit volume could be done on a material prior to rupture. Unfortunately the concept of toughness could not give a clear trend of SAT test results. Since SAT test results were affected unpredictably by a tiny variation of hydride distribution along the cracking path, the worst-case data of each test batch were selected to assess the effect of radial hydride on the hoop mechanical properties of Zircaloy-4 cladding conservatively. The SAT test results were re-plotted in Fig. 11. The concentration of radial
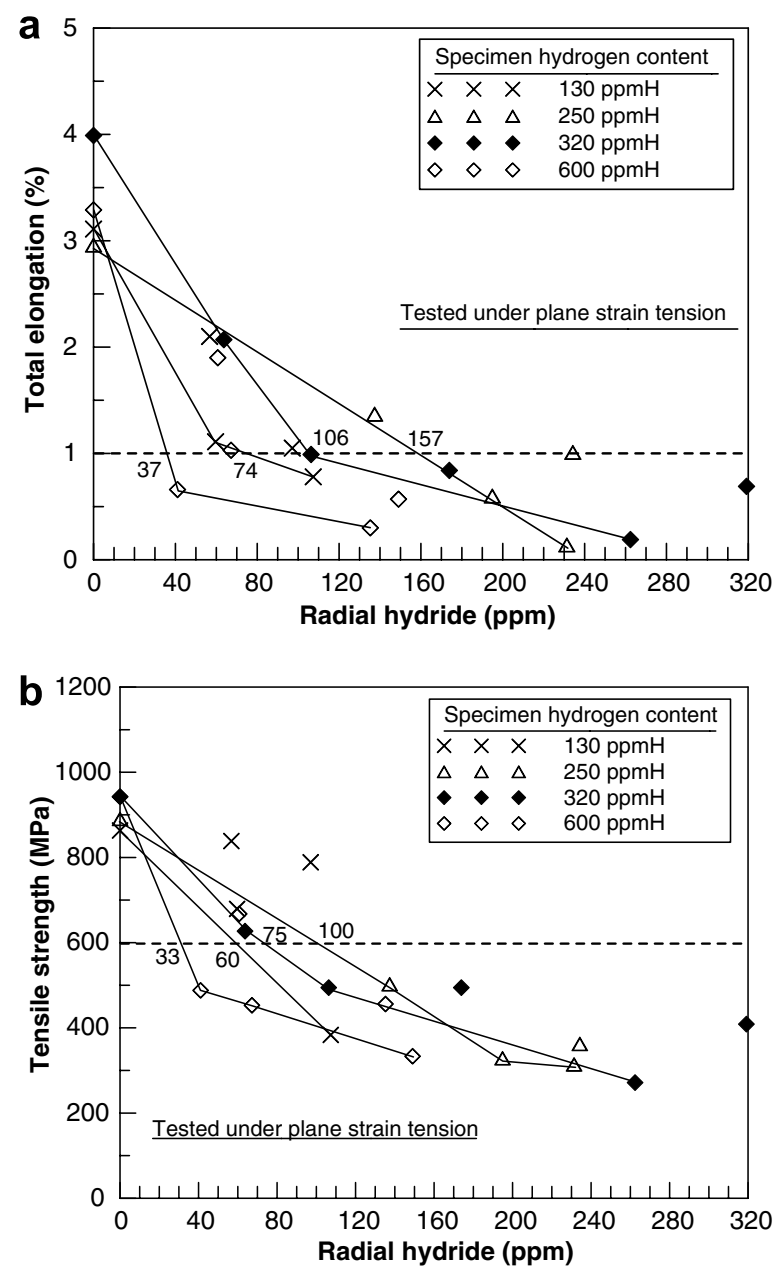

Fig. 11. Determination of the reference radial hydride concentration of Zircaloy-4 cladding material by the acceptance criteria of (a) $1 \%$ total strain and (b) tensile strength of $600 \mathrm{MPa}$. hydride in Fig. 11 was obtained by multiplying the percentage of radial hydride and the bulk hydrogen content of the specimen. A residual strain of 0.01 was commonly used as an acceptance criterion in evaluating the integrity of fuel cladding, so $1 \%$ total elongation was taken as a reference value in Fig. 11(a). It was found that cladding specimens failed to meet this criterion when radial hydride concentrations (reference concentrations) were higher than 74, 157, 106, and $37 \mathrm{wt} \mathrm{ppm}$ for the specimens with bulk hydrogen contents of 130 , 250, 320 and $600 \mathrm{wt}$ ppm, respectively. Because of the fact that the surface crack probably occurred during SAT testing, the reference concentration of radial hydrides determined by cladding ductility might not be conservative. As shown in Fig. 6, the yield strength of an intact Zircaloy-4 specimen (i.e. without surface crack) under plane strain condition was $\sim 600 \mathrm{MPa}$. For this reason, a tensile strength level of $600 \mathrm{MPa}$ was chosen as an alternative acceptance criterion to determine the reference concentrations conservatively. The reference radial hydride concentrations determined by $600 \mathrm{MPa}$ for the specimen at each hydrogen level were 60, 100, 75 , and $33 \mathrm{wt}$ ppm, respectively (Fig. 11(b)). The results are summarized in Table 2. The reference radial hydride concentrations obtained in this work are comparable to those reported by Marshall and Louthan on the annealed Zircaloy-2 specimens with total hydrogen less than $\sim 200 \mathrm{wt}$ ppm $[1,4]$. They suggested that all specimens with radial hydrides containing more than $50 \mathrm{wt}$ ppm $\mathrm{H}$ exhibited no macroscopic ductility. It should be noted that the engineering strain was less than $1 \%$ when the yield point was reached during a 'normal' SAT testing (a test with no surface crack occurring). The reference radial hydride concentrations determined by the cladding tensile strength were more conservative and reliable than those by the cladding ductility.

Table 2

Reference concentrations of radial hydrides for brittle fracture of SRA Zircaloy-4 cladding with different hydrogen content levels tested under slotted arc tension

\begin{tabular}{|c|c|c|c|c|}
\hline \multirow[t]{3}{*}{ Specimen } & \multicolumn{4}{|c|}{ Reference concentrations } \\
\hline & \multicolumn{2}{|c|}{$\begin{array}{l}\text { Determined by } \\
1 \% \text { strain }\end{array}$} & \multicolumn{2}{|c|}{$\begin{array}{l}\text { Determined by } \\
600 \mathrm{MPa} \text { stress }\end{array}$} \\
\hline & (wt ppm) & $(\%)$ & (wt ppm) & $(\%)$ \\
\hline 130 wt ppm H specimen & 74 & 56.9 & 60 & 46.2 \\
\hline 250 wt ppm H specimen & 157 & 62.8 & 100 & 40.0 \\
\hline 320 wt ppm H specimen & 106 & 33.1 & 75 & 23.4 \\
\hline $600 \mathrm{wt} \mathrm{ppm} \mathrm{H}$ specimen & 37 & 6.2 & 33 & 5.5 \\
\hline
\end{tabular}


One factor that determines the mechanical properties of cladding specimens is the continuity of hydride precipitates. As reported by Arsene et al. [3], a ductile-brittle transition occurred when a critical inter-hydride spacing reached and the transition happened within a range of hydrogen contents (from 1500 to $2400 \mathrm{ppm}$ ). This work indicated, when parts of the circumferential hydrides became radial, the chance to form a continuous hydride network increased. However, the probability to reach the critical spacing between circumferential hydrides also decreased because some of hydrides were consumed as the reorientation process happened. It can be confirmed by comparing the hydride spacings in the specimens of the same hydrogen level but with different radial hydride contents. The continuity of hydrides and the inter-hydride spacing were the two factors interacting with each other in a complicated way to affect the deformation behavior of Zircaloy cladding under slotted arc tension, which was reflected in wide variations of SAT test results from specimen to specimen.

From the data shown in the last column of Table 2 , the reference percentage of radial hydrides linearly decreased with increasing specimen hydrogen content. The reference hydrogen concentration increased with the specimen (bulk) hydrogen concentration to a maximum of $\sim 90 \mathrm{wt}$ ppm at the bulk concentration $\sim 300$ wt ppm $\mathrm{H}$ and then decreased towards higher concentrations, as plotted in Fig. 12. It could be accounted for by the hypothesis that a large percent of radial hydrides are needed to develop continuous cracking path due to the large

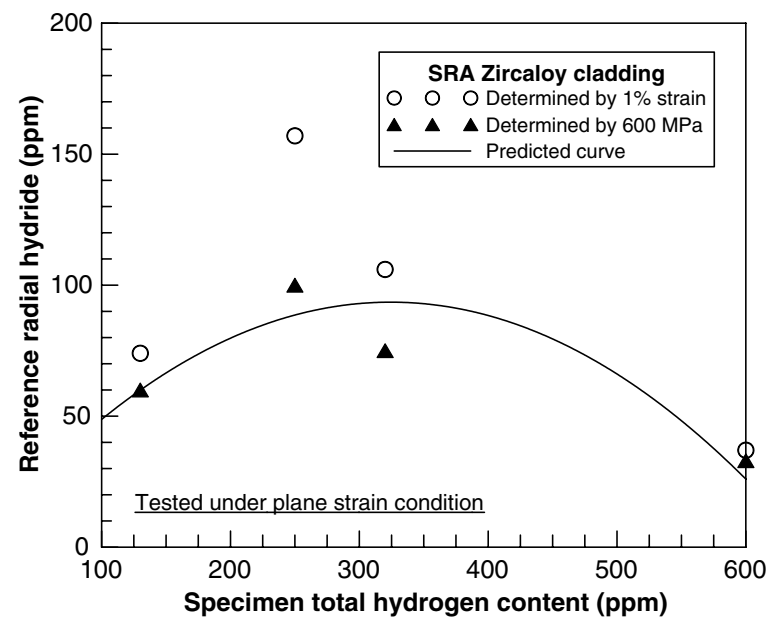

Fig. 12. Estimation of the reference radial hydride concentration as a function of specimen total hydrogen concentration. inter-hydride spacings in the specimens of lower hydrogen contents, and that in the specimens of higher hydrogen contents, a reduction in hydride spacing would make it easier to link neighboring hydrides together with a demand for fewer radial hydrides to form a continuous network along the cracking (Fig. 13). Besides, circumferential hydrides would also work to exacerbate the brittle behavior when a cladding specimen had very high hydrogen contents. These results suggest that a small amount of radial hydrides can be extremely detrimental to
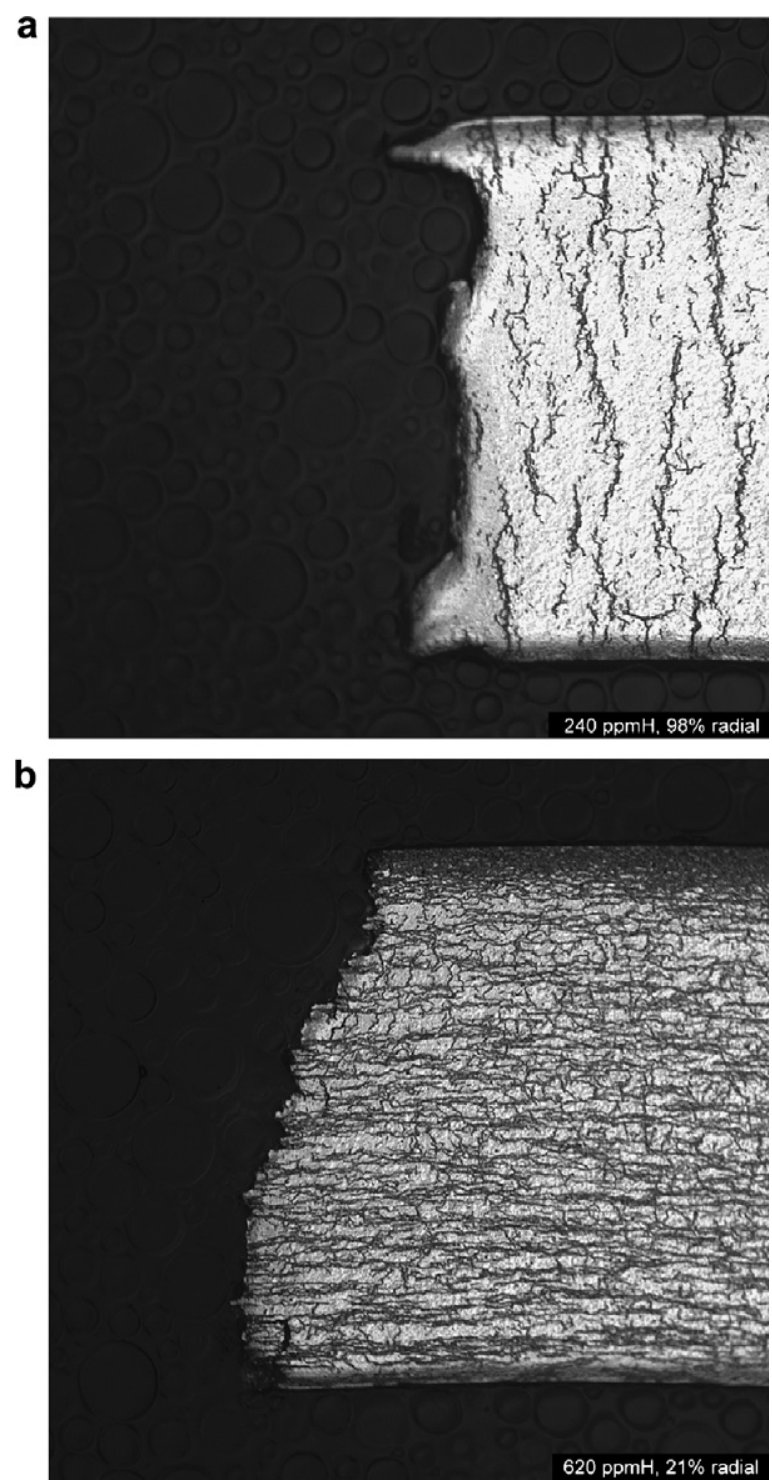

Fig. 13. Cross-sections of Zircaloy-4 cladding specimens tested under slotted arc tension at room temperature: (a) $240 \mathrm{wt}$ ppm $\mathrm{H}$ specimen with $98 \%$ radial hydrides, and (b) $620 \mathrm{wt} \mathrm{ppm} \mathrm{H}$ specimen with $\sim 21 \%$ radial hydrides. 
the integrity of cladding materials of higher hydrogen concentrations although they are difficult to be formed.

\section{Conclusions}

In this study, the hydride reorientation behavior and the effects of radial hydrides on the axial and hoop mechanical properties were investigated. Summarized below are the results:

1. Hydrided specimens with bulk hydrogen contents from 130 to $600 \mathrm{wt}$ ppm were thermally cycled in an autoclave under a constant hoop stress. The percentage of radial hydrides increased as the number of thermal cycles increased until it reached a saturated value. More than $90 \%$ of hydride precipitates in the $200-300 \mathrm{wt} \mathrm{ppm} \mathrm{H}$ specimens were reoriented into the radial direction after several thermal cycles.

2. The hydride-reoriented cladding specimens with bulk hydrogen contents from 130 to $600 \mathrm{wt}$ ppm were tested in uniaxial tension at room temperature. The effect of radial hydrides on the axial ductility of cladding tube can be neglected.

3. The effects of radial hydrides on the hoop tensile properties of Zircaloy-4 cladding specimens with hydrogen concentration levels up to $600 \mathrm{wt} \mathrm{ppm}$ were tested at room temperature using slotted arc tensile specimens. Test results were scattered but indicated a trend that mechanical properties degraded with increasing percentage of radial hydrides.

4. The reference concentration of radial hydrides for brittle fracture of cladding material increased as the total hydrogen content increased to about $300 \mathrm{wt}$ ppm and then decreased with increasing hydrogen concentration. The results in this study suggest that a small amount of radial hydrides can be extremely detrimental to the integrity of cladding materials of higher hydrogen concentrations although they are difficult to be formed.

\section{References}

[1] R.P. Marshall, M.R. Louthan Jr., Trans. ASM 56 (1963) 693.

[2] J. Bai, C. Prioul, D. Francois, Metall. Mater. Trans. A 25 A (1994) 1185.

[3] S. Arsene, J.B. Bai, P. Bompard, Metall. Mater. Trans. A 34A (2003) 579.

[4] M.R. Louthan Jr., R.P. Marshall, J. Nucl. Mater. 9 (1963) 170.

[5] C.E. Ells, J. Nucl. Mater. 35 (1970) 306.

[6] M. Leger, A. Donner, Can. Metall. Q. 24 (1985) 235.

[7] H.M. Chung, in: Proceedings of the International Meeting on LWR Fuel Performance, Orlando, FL, 19-22 September 2004.

[8] G. Domizzi, G. Vigna, S. Bermúdez, J. Ovejero-García, J. Nucl. Mater. 275 (1999) 255.

[9] S. Shimada, E. Etoh, H. Hayashi, Y. Tukuta, J. Nucl. Mater. 327 (2004) 97.

[10] E.W. Brach, Cladding considerations for the transportation and storage of spent fuel, Interim Staff Guidance-11, Revision 3, US NRC, Spent Fuel Project Office, 2003.

[11] J.J. Kearns, J. Nucl. Mater. 22 (1967) 292.

[12] D. Lee, R.B. Adamson, in: A.L. Lowe Jr., G.W. Parry (Eds.), Zirconium in Nuclear Industry, ASTM STP-633, American Society for Testing and Materials, 1977, p. 385.

[13] D. Lee, Trans. ASM 61 (1968) 742.

[14] D. Lee, W.A. Backofen, Trans. Met. Soc. AIME 236 (1966) 1077.

[15] R.C. Kuo et al., EPRI Report, TR-108753-P2, 2000.

[16] J.-H. Huang, S.-P. Huang, J. Nucl. Mater. 208 (1994) 166.

[17] R. Choubey, M.P. Puls, Metall. Mater. Trans. A 25A (1994) 993.

[18] G.E. Dieter, Mechanical Metallurgy, McGraw-Hill Book Company, London, 1988. 